\title{
El medio ambiente en la televisión española: análisis de un año de informativos
}

\author{
Luis Pablo FrancescutTI \\ Universidad Rey Juan Carlos de Madrid \\ luispablo.francescutti@urjc.es \\ Fernando Tucho FERnÁndeZ \\ Universidad Rey Juan Carlos de Madrid \\ fernando.tucho@urjc.es \\ Ana Isabel IÑIGO JURADO \\ Universidad Rey Juan Carlos de Madrid \\ anaisabel.inigo@urjc.es
}

Recibido: $31 / 10 / 2012$

Aceptado: 23/07/2013

\section{Resumen}

La televisión encabeza las fuentes a través de las cuales la sociedad se informa sobre el medio ambiente; sin embargo, existen muy pocos estudios cuantitativos de su cobertura. Paliar esa laguna es el objetivo del análisis de los informativos españoles que aquí se presenta. De una muestra de 32.592 noticias recogidas durante un año, las informaciones de temática ambiental supusieron un 3,4\% del total. Centradas en el deterioro del ecosistema, el estado de la biodiversidad, el cambio climático, las prácticas ecosaludables, la protesta ecológica y las energías renovables, dichas piezas tuvieron por valores noticiosos el catastrofismo, el dramatismo, el atractivo visual y el conflicto. Su flujo regular a lo largo del periodo estudiado indica que el medio ambiente ha conquistado un nicho permanente en el espacio prime time de la programación.

Palabras clave: Medio ambiente, informativos televisivos, España, análisis de contenido

\section{Spanish television news coverage of environmental issues. A Content Analysis of one year of News Programs}

\begin{abstract}
In many Western countries, television is the main source of environmental information. Despite its importance, there are few quantitative studies of these coverage. Our aim is to analyze the Spanish television news in order to alleviate the lack of information regarding this subject. From a sample of 32,592 news collected throughout a one-year period, we found that information on environmental issues accounted for $3.4 \%$ of the total. These news focused on the following topics: ecosystem deterioration, biodiversity, climate change, eco-friendly practices, ecological protest and renewables. A common thread runs through the coverage: a tendency towards catastrophism, drama, visual appeal and conflict. It can be said that its regular flow during the study period indicates that environmental topics have won a permanent niche in prime-time programming.

Keywords: Environment, news programs, television, content analysis, Spain

\section{Referencia normalizada}

FRANCESCUTTI, Luis Pablo; TUCHO FERNÁNDEZ, Fernando; ÍNIIGO JURADO, Ana Isabel (2013): "El medio ambiente en la televisión española: análisis de un año de informativos". Estudios sobre el Mensaje Periodístico. Vol. 19, Núm. 2 (julio-diciembre), págs.: 683-701. Madrid, Servicio de Publicaciones de la Universidad Complutense.
\end{abstract}

Sumario: 1. Introducción. 2. Método aplicado; 2.1. Unidad de análisis; 2.2. Criterio de selección; 2.3. Pasos metodológicos. 3. Resultados; 3.1. La cobertura en cifras; 3.2. Procedencia de las noticias am- 
bientales; 3.3. Tópicos informativos; 3.3.1 Deterioro del ecosistema; 3.3.2. Biodiversidad; 3.3.3. Cambio climático; 3.3.4. Prácticas ecosaludables; 3.3.5. Protestas por motivos ambientales; 3.3.6. Energías renovables; 3.4. La agenda ambiental. 4. Discusión; 4.1. Relevancia numérica; 4.2. Origen de las noticias; 4.3. Contenidos de las noticias; 4.4. Criterios de noticiabilidad. 5. Conclusiones. 6. Referencias.

\section{Introducción ${ }^{1}$}

Los medios de comunicación tienen gran capacidad para modelar el discurso público sobre el medio ambiente y las percepciones que del mismo manejan las audiencias. Es a través de la esfera mediática como las sociedades industrializadas obtienen conocimiento sobre su entorno (Curtin \& Rhodenbaugh, 2001; Weingart \& Engels, 2000; Szerszynski \& Toogood, 2000). En España, en concreto, el 71\% de la población depende de los medios para conocer la problemática ambiental (Díez Nicolás, 2004).

Prensa y televisión en particular constituyen las principales fuentes de información ambiental de las audiencias, tanto en Estados Unidos (Ostman \& Parker, 1987; Pew Study, 2006), como en lugares remotos como Malasia (Haron et al., 2005) u Omán (Abdul-Wahab, 2008). En España también es la pequeña pantalla el medio más empleado por la población para informarse sobre el ambiente (Díez Nicolás, ídem).

Los informativos en particular son el formato televisivo a través del cual el público adquiere conocimientos sobre esa materia, tanto en Estados Unidos (Wilson, 1995) como en Europa, siendo la primera fuente de información ambiental para el $64 \%$ de la población, por delante de prensa, Internet y radio (Comisión Europea, 2007).

Pese a su importancia, las noticias televisivas de contenido ambiental no han sido analizadas exhaustivamente. Se ha estudiado la cobertura del cambio climático (Lester \& Cottle, 2009) y de las cumbres del clima (Mikami, 1995), la retórica ambiental de la serie The Simpsons (Todd, 2002) o el poder de la televisión para impulsar la conciencia ambiental (Brothers et al., 1991; Good, 2009); se han estudiado las alusiones ambientales en programas de ficción (McComas et al., 2001), en anuncios (Peterson, 1991), en la programación prime time (Shanahan \& McComas, 1997) y en toda clase de programas (Carabaza et al., 2007); pero los estudios cuantitativos centrados en el componente ambiental de los informativos son escasos. Entre estos pocos cabe citar el de Prasad et al. (2009) sobre una muestra de 14 días de la televisión malaya, el de León (2007) sobre una muestra de doce semanas de la televisión española y el de Mercado Sáez (2010), que abarca dos meses de los mismos programas.

Faltan investigaciones que cubran períodos más largos, capaces de medir con fiabilidad y al margen de variaciones puntuales la atención prestada a la crisis ambiental, y de determinar si su cobertura enfatiza el espectáculo o la prevención, entre otros parámetros. Este tipo de estudio resulta necesario puesto que, como postula la teoría de la agenda-setting (Roberts \& McCombs, 1994), los medios influyen en la sociedad

1 Este trabajo recoge los resultados del contrato de investigación "El tratamiento de la crisis ambiental y el cambio climático", financiado por la Asociación de Periodistas de Información Ambiental (APIA) 
al seleccionar los temas de los cuales la población hablará o pensará; de lo que se sigue que el grado de presencia mediática de la temática ambiental decidirá en gran medida el conocimiento y la importancia que el público le confiera.

El trabajo que aquí se presenta intenta cubrir esa laguna a partir del análisis de los informativos televisivos españoles. Sus pautas de cobertura poseen gran interés de cara a la comunicación ambiental por desarrollarse en el seno de un país industrializado con una valiosa biosfera ${ }^{2}$ en proceso de deterioro ${ }^{3}$; una nación en donde el debate ecológico ha alcanzado una madurez palpable en la existencia de un Ministerio del Medio Ambiente y en el alto grado de especialización periodística en la materia (prueba de ello es la Asociación de Periodistas de Información Ambiental, activa desde 1994).

Tales antecedentes justifican la elaboración de una 'radiografía' de las noticias ambientales en las cadenas españolas, que ayude a dilucidar la 'dieta' informativa que dan al público y aporte una base empírica al debate sobre la contribución del medio audiovisual a la comprensión de la crisis ambiental.

Presentar dicho diagnóstico constituye el objeto de este artículo. En él se exponen los resultados de un estudio comparativo de la cobertura de los informativos primetime (los emitidos en el horario de mayor audiencia, que en España se inicia a las 21:00hs) de cuatro cadenas españolas a lo largo de un año. Aparte de cuantificar la información ambiental e identificar su repertorio de temas y su jerarquía, los datos generados ilustran los contenidos más habituales y los criterios de noticiabilidad manejados por los editores de los programas. Asimismo, permiten someter a prueba el postulado de la apropiación del discurso ambiental por parte los medios de comunicación, formulado por la teoría de la 'modernización ecológica' (Oltra, 2005).

\section{Método aplicado}

El análisis de contenido tal como lo entiende el análisis funcional (Krippendorff, 1980; Kolbe \& Burnett, 1991) fue aplicado a una muestra integrada por todas las noticias emitidas por la segunda edición de los informativos de las siguientes cadenas españolas de ámbito nacional: Televisión Española-TVE1 (pública), Antena 3-A3, Tele5 y Cuatro (privadas) ${ }^{4}$. El periodo estudiado abarcó un año entero, desde el 1 de abril

2 España alberga tres cuartas partes de las aves y dos tercios de los vertebrados europeos, con el mayor número de especies autóctonas del continente. Es el segundo país de la UE con mayor superficie forestal; y también el segundo en número de Humedales de Importancia Internacional (Convención Ramsar). En el mundo es el tercer país con más reservas de la biosfera declaradas por UNESCO (v. Martín López, 2011).

3 En 2007, era el tercer país de Europa que acumulaba más superficie forestal quemada desde 1998, según el Observatorio de la Sostenibilidad en España (2008:108).

4 Dichas cadenas eran las emisoras de ámbito nacional más vistas al inicio del periodo estudiado. En abril de 2007, congregaban el $62,7 \%$ de la audiencia, desglosada de la siguiente manera: Tele 5, 20,1\%; A3, 17,5\%; TVE1, 17,3\%; y Cuatro, 7,8\% (datos de la auditora TNS Sofres). 
de 2007 hasta el 31 de marzo de 2008 inclusive $^{5}$. Se trata de un periodo suficientemente prolongado como para ofrecer un retrato fidedigno de la cobertura habitual y minimizar las distorsiones que podría provocar un macro-acontecimiento ${ }^{6} \mathrm{en}$ un lapso más corto.

\subsection{Unidad de análisis}

La unidad escogida fue la noticia, es decir una unidad portadora de información que alude a un acontecimiento con sentido en sí mismo y con un titular propio. Para la muestra se seleccionaron todas las unidades informativas en sus distintas variantes (noticia, crónica, entrevista, reportaje), dejando fuera las piezas de opinión. En el caso de los bloques compuesto por piezas que trataban distintos aspectos de un mismo tema con titulares diferentes, cada una de ellas fue sometida a un análisis individual.

\subsection{Criterio de selección}

Se analizaron todas las noticias relacionadas con el ambiente en el sentido más amplio: políticas públicas, novedades respecto del cambio climático, estado de los mares, impacto del urbanismo, sequía, degradación del medio natural, acciones de concienciación, medidas y actividades ecosaludables, galardones al compromiso ambiental, hallazgos científicos sobre la salud de los ecosistemas y de las especies vivientes, productos ecológicos, protestas contra la contaminación, etcétera.

Se excluyeron las noticias de animales que no aludieran expresamente a cuestiones ambientales (del estilo: "Atacados por una tigresa escapada del Zoo de San Francisco"). De igual modo se obviaron las relativas a desastres naturales (huracanes, volcanes) que no se imputasen a la agencia humana, junto con las referentes a armas nucleares, por hallarse enmarcadas en la política internacional.

\subsection{Pasos metodológicos}

Los informativos fueron grabados por el Laboratorio de Investigación de la Imagen Televisiva y Electrónica (LITTE) de la Universidad Rey Juan Carlos de Madrid. Un equipo del Grupo de Estudios Avanzados de Comunicación (GEAC), de la misma universidad, se encargó de codificar las noticias y procesar los datos generados. El primer paso consistió en el visionado de las 1.200 horas de grabaciones obtenidas y en la clasificación preliminar de las noticias. Con las piezas catalogadas como ambien-

5 De la muestra faltan algunos días: A3 canceló las noticias los días 3, 5, 10, 12, 24, y 26 de abril, y 2 de octubre de 2007 para emitir partidos de fútbol; Tele 5 hizo lo propio el 20 de octubre; y por idéntica razón TVE apenas emitió cinco minutos de noticias el 5 de octubre y anuló el informativo del 21 de noviembre.

6 Ejemplo de hecho distorsionador: el accidente del petrolero Prestige el 13 de noviembre de 2002 frente a la costa gallega. Su marea negra causó una de las catástrofes ambientales más grandes de la historia de la navegación, tanto por la cantidad de contaminantes como por las extensiones afectadas. El siniestro desató en España una crisis política y una gran controversia pública. En la fase crítica, las cadenas nacionales le dedicaron entre el 30 y $70 \%$ del tiempo de sus informativos (Vicente, 2005:155). 
tales se estableció el corpus definitivo, cuyo análisis y codificación se realizó a continuación.

La ficha de codificación constaba de seis grandes tópicos: "Deterioro del ecosistema"; "Biodiversidad"; "Cambio Climático"; "Prácticas ecosaludables"; "Protestas por motivos ambientales"; "Energías Renovables"; y un apartado residual, "Otros contenidos". Fueron elegidos en función de aspectos considerados más relevantes en una cobertura de estas características: la atención al cambio climático; el impacto de las protestas y de las medidas de protección; la denuncia de los estragos ecológicos; la educación ambiental; y la preocupación por las especies vivientes.

Con la finalidad de facilitar un conocimiento más detallado de los contenidos, cada tópico fue dividido en sub-tópicos más específicos (en total 34 categorías).

Para el análisis de contenido se entrenó a ocho codificadores ${ }^{7}$ a lo largo de varias sesiones. Antes de acometer la codificación definitiva se realizaron ejercicios y verificaciones cruzadas con el propósito de reducir ambigüedades y establecer criterios de codificación similares. Las pruebas de fiabilidad entre codificadores obtuvieron un acuerdo de media superior al $80 \%$, un valor juzgado adecuado. Los datos producidos fueron introducidos en una matriz SPSS, cuyo procesamiento arrojó los resultados que se ofrecen en las páginas siguientes.

\section{Resultados}

\subsection{La cobertura en cifras}

En el periodo estudiado los informativos prime-time de las cuatro cadenas emitieron un total de 32.592 noticias, de las cuales $1.124(3,45 \%)$ eran ambientales. A continuación, se exponen esos resultados desglosados por cadenas.

\begin{tabular}{|l|c|c|c|}
\hline \multicolumn{4}{|c|}{ Tabla 1: número de noticias ambientales por cadena } \\
\hline Cadena & $\begin{array}{c}\mathrm{N}^{\mathrm{o}} \text { total de } \\
\text { noticias emitidas }\end{array}$ & $\begin{array}{c}\mathrm{N}^{\mathrm{o}} \text { de } \\
\text { noticias ambientales }\end{array}$ & $\begin{array}{c}\% \text { de noticias ambientales } \\
\text { sobre total de noticias }\end{array}$ \\
\hline TVE 1 & 8.871 & 339 & $3,82 \%$ \\
\hline CUATRO & 7.055 & 277 & $3,93 \%$ \\
\hline ANTENA 3 & 9.042 & 258 & $2,85 \%$ \\
\hline TELE5 & 7.624 & 250 & $3,28 \%$ \\
\hline TOTAL & 32.592 & 1.124 & MEDIA: 3,45 \\
\hline
\end{tabular}

TVE1 fue la que más noticias ambientales emitió, seguida de Cuatro, A3 y Tele5. En términos relativos, los porcentajes de tales noticias sobre el total de informaciones

${ }^{7}$ El equipo lo formaron Mirian Meda, Lunice Bajotto, Jorge Biancotti, Sherezade Alvarez, Verónica Ramírez, Esther Paniagua, Jessica Pleguezuelos y Sonia Vega, a quienes agradecemos su valiosa colaboración, así como a los profesores José Ramón Santillán y Manuel Martínez Nicolás por su ayuda en el diseño de la matriz SPSS. 
emitidas oscilaron entre el 2,85 y el 3,93\%, una horquilla tan estrecha que no autoriza a hablar de diferencias significativas entre los informativos.

Otro parámetro del valor periodístico asignado a estos contenidos lo ofrecen los titulares mencionados al inicio de cada programa, el denominado sumario (la 'primera plana' del informativo). A juicio de los editores, las piezas destacadas en este tramo revisten mayor relevancia o atractivo que las restantes. El cómputo efectuado arrojó que el 37,3 de estas informaciones fueron citadas en los sumarios. Desde este ángulo resulta que el informativo de A3 fue el que más resaltó sus noticias ambientales, ya que incluyó al 40,3\% de ellas en sus sumarios, seguido del de Tele 5 (38,4\% de informaciones citadas en los principales titulares), Cuatro $(38,3 \%)$ y TVE $(32,2 \%)$. En la primacía de A3 posiblemente pesó su apuesta editorial por todo tipo de desastres (abona esta hipótesis el hecho de que la cadena llevase al 62\% de los incendios forestales a sumarios, un porcentaje superior a las demás). La televisión pública, la que más noticias de esta clase emitió, fue la que menos jerarquía les otorgó.

\subsection{Procedencia de las noticias ambientales}

El $64,7 \%$ de las noticias identificadas aludía a acontecimientos ocurridos en España, y el resto a hechos producidos fuera de sus fronteras. Desglosando los tópicos según la procedencia de las informaciones, tenemos que el 71,9\% de las noticias de "Cambio climático" procedía del exterior, al igual que el 56,8\% de las de "Energías renovables"; mientras que en España se originaron mayormente las piezas de "Prácticas ecosaludables" (76,7\% del total), "Biodiversidad" (74,8\%), "Protestas por motivos ambientales" (73,6\%) y "Deterioro del ecosistema" (67,8\%). En otras palabras: los contenidos de "Cambio climático" y "Energías renovables" fueron 'importados'; en los demás tópicos las cadenas se abastecieron con lo acontecido en territorio nacional.

\subsection{Tópicos informativos}

A continuación, las noticias ambientales clasificadas con arreglo a los tópicos citados:

Tabla 2: Tópicos de la información ambiental

\begin{tabular}{c|c|c|}
\hline \multicolumn{1}{|c}{ Tópico } & $\begin{array}{c}\text { Número de } \\
\text { noticias }\end{array}$ & Porcentaje \\
\hline Deterioro del ecosistema & 435 & $38,7 \%$ \\
\hline Biodiversidad & 293 & $26,1 \%$ \\
\hline Cambio climático & 154 & $13,7 \%$ \\
\hline Prácticas ecosaludables & 122 & $10,8 \%$ \\
\hline Protestas por motivos ambientales & 74 & $6,6 \%$ \\
\hline Energias Renovables & 36 & $3,2 \%$ \\
\hline Otros contenidos & 10 & $0,9 \%$ \\
\hline Total & $\mathbf{1 . 1 2 4}$ & $\mathbf{1 0 0}$ \\
\hline
\end{tabular}

"Deterioro del ecosistema" fue el tópico más frecuente, seguido de "Biodiversidad", "Cambio climático", "Prácticas ecosaludables", "Protestas por motivos ambientales", "Energías renovables" y "Otros contenidos". A continuación examinaremos 
cada uno de ellos junto con sus respectivos sub-tópicos e intentaremos dar cuenta de su jerarquía.

\subsubsection{Deterioro del ecosistema}

Se desglosa en los sub-tópicos "Incendios forestales"; "Vertidos marítimos y otras contaminaciones"; "Sequía"; "Impacto ecológico del urbanismo"; "Deforestación"; y "Riesgo de irradiación".

"Incendios forestales" predomina con el 45,5\% de las noticias del tópico. Dos razones concurren para explicar su preeminencia: 1) la estacionalidad: en España tales siniestros se concentran en verano, temporada de 'sequía informativa', siendo muy valorados por editores necesitados de noticias (solo en julio y agosto de 2007 se emitieron 148 noticias de incendios, el 74,7\% de este sub-tópico); y 2) la espectacularidad: los bosques en llamas son visualmente atractivos y dramáticos; lo prueba el hecho de que el $51 \%$ de estas noticias fuera incluido en sumarios ${ }^{8}$. El ínfimo espacio dedicado a "Desforestación" ( $0,9 \%$ de las noticias) revela que la pérdida de patrimonio forestal le interesa a las cámaras cuando asume expresiones sobrecogedoras.

El segundo lugar le toca a "Vertidos marítimos y otras contaminaciones", con un $34,7 \%$. Este porcentaje se reparte entre derrames de hidrocarburos $(27,8 \%)$ y emanaciones tóxicas, vertidos en ríos, etcétera (6,9\%). A cinco años del desastre del Prestige, el recuerdo del daño causado por los vertidos se mantenía presente en los periodistas, pese a que en el lapso estudiado no se registraron derrames de gran magnitud.

"Sequía" ocupa un tercer lugar (13,3\%), un dato congruente con el país más árido de Europa. A su posición contribuyó el empeoramiento del régimen hídrico (sobre todo en Cataluña) registrado a finales del periodo estudiado.

Con 3,7\% de las noticias, "Riesgo de irradiación" ocupa el quinto puesto. Dado que en el periodo cubierto no hubo incidentes graves en las centrales nucleares españolas, el dato expresaría la persistente sensibilidad periodística al riesgo atómico.

Sorprende la penúltima posición del "Impacto ecológico del urbanismo" (1,8\% de las informaciones), a la vista de la devastación causada al entorno español por la especulación inmobiliaria, objeto de sendos informes del Parlamento Europeo de 2005 y 2007 respectivamente.

\subsubsection{Biodiversidad}

El segundo tópico en volumen es "Biodiversidad", relativo al estado de la fauna y la flora, a las amenazas que se ciernen sobre ambas, y a los daños causados por la acción humana y a su remediación, y se divide en los siguientes sub-tópicos:

"Alteración de hábitos y hábitats" (38,3\% de estas noticias) se refiere a conductas o desplazamientos inusuales de la fauna, interpretados como síntomas de perturba-

${ }^{8}$ El alto número de noticias de incendios no guarda proporción con la realidad: "los datos del año 2007 indican que [...] El número de siniestros ha sido inferior a los diez años anteriores, debiendo remontarse 19 años atrás hasta 1988 para encontrar un valor inferior, año en que se produjeron 9.247 siniestros frente a los 10.932 de 2007. [...] las cifras de superficie forestales recorrida por el fuego presentan valores inferiores de la media del decenio" (Ministerio de Agricultura, Alimentación y Medio Ambiente, 2007:7). 
ciones en sus ecosistemas (ej.: las plagas de medusas, una consecuencia de la desaparición de sus depredadores a causa de la pesca excesiva). En su abultado número habrían influido tanto la preocupación por estas alteraciones como su valor de infoentretenimiento (jabalíes que invaden hogares, tiburones en playas catalanas...).

La segunda posición la ocupa "Cría en cautividad de animales amenazados", (21,4\% de las noticias) referente a programas de reproducción de tales especies. Propicia estas informaciones la cercanía de zoos y centros de cría, fuente continua de novedades e imágenes exóticas (solo los osos pandas del zoo de Madrid dieron pie a 20 noticias). Si a este rubro se le suma "Especies amenazadas" (15,6\% de las noticias), alusivo a animales en estado salvaje cuya supervivencia peligra, tendremos que la fauna amenazada generó 109 noticias, situándose prácticamente a la par de "Alteración de hábitos y hábitats". Estos tres sub-tópicos comparten un valor periodístico muy cotizado, el de la rareza (Muñoz Torres, 2002), puesto que son raras muchas especies en peligro, y raros son los comportamientos de algunas criaturas.

En cuarto lugar figura "Maltrato de animales" (14,2\% de las noticias), aunque su número subiría de 42 a 53 piezas de sumársele las quejas similares incluidas en "Protestas por motivos ambientales". La cobertura de los sufrimientos infligidos a mascotas y animales de granja o laboratorio, y de las acciones de los animalistas, refleja la consolidación de los 'derechos de los animales' en la agenda periodística.

Le sigue "Tráfico ilegal de especies" ( $4,4 \%$ de las piezas del tópico), cuya presencia acredita la preocupación periodística por el bienestar animal y la eficacia de los organismos policiales para difundir sus actuaciones contra esta práctica nefasta. Por último, "Hallazgos científicos sobre la biodiversidad" ( $2,7 \%$ de las noticias). La escasa cuantía de estos descubrimientos de carácter naturalista mueve a pensar que, pese a la afición de la televisión por los animales, a este medio le atraen más las vicisitudes de la fauna -por su dramatismo- que un mejor conocimiento de ella.

La situación de las plantas apenas mereció un 2,3\% de los contenidos del tópico. El altísimo número de especies vegetales amenazadas o en peligro de extinción no cuadra con su bajísima representación televisiva, una posible consecuencia del énfasis depositado por televisiones y ecologistas en los animales, seres mucho más telegénicos.

\subsubsection{Cambio climático}

Este apartado se desglosa en los siguientes sub-tópicos:

"Medidas Oficiales", el más abultado (34,4\% de las noticias), comprende las disposiciones gubernamentales españolas, extranjeras y de organismos internacionales dirigidas a encarar el cambio climático (el Tratado de Kioto, por citar un caso). Que este sub-tópico supere a "Nuevos Datos Científicos" (27,9\% de las noticias) revela que la información politizada (actuaciones oficiales, cumbres del clima) interesó más que los hallazgos de la ciencia respecto del cambio global y su evolución, aunque estos últimos ocuparon un respetable segundo lugar, al cual puede haber coadyuvado su presentación en cónclaves avalados por la ONU.

El tercer sitio le toca a "Iniciativas ciudadanas" (20,8\% de las noticias): acciones contra el cambio climático promovidas por colectivos, ONGs o individuos. El cuarto 
lugar lo compartieron "Impacto en la Biodiversidad" (repercusiones en la fauna y flora del calentamiento global) y "Otras medidas contra el cambio climático" (acciones que no encajan en los apartados anteriores), con el 5,8\% de las noticias cada uno.

Merece la pena apuntar que las televisiones estudiadas no se hicieron eco de los "negacionistas" del cambio climático, y en cambio ofrecieron sus tribunas a los defensores de la hipótesis de su origen antrópico. En contraste con los medios estadounidenses (v. Antilla, 2005), los españoles no negaron el calentamiento global.

En general, en este tópico primó la cobertura del proceso de deliberación y toma de decisiones y de divulgación de nuevos conocimientos, en lugar del catastrofismo asociado a "Deterioro del ecosistema".

\subsubsection{Prácticas ecosaludables}

Bajo este tópico agrupamos las noticias sobre cualquier clase de medidas y acciones dirigidas a concienciar y reducir la degradación ambiental (excluyendo las acciones tendentes a atajar el cambio climático, mencionadas en el apartado anterior).

"Acciones de concienciación" (39,3\%) constituyen el grupo más numeroso. Aquí se recogen desde denuncias de daños ecológicos a la promoción de programas televisivos y películas ambientalistas y la entrega de distinciones por administraciones públicas, empresas, ciudadanos y ONGs (estas últimas mediante vistosas iniciativas como los festejos del Día de la Tierra o las mediáticas intervenciones de Greenpeace).

El siguiente apartado, "Medidas gubernamentales" (37,7\% de las noticias), incluye actuaciones concretas de protección ambiental ejecutadas por administraciones públicas españolas y extranjeras (cierre de fábricas contaminantes, reciclado obligatorio). En el predominio de las primeras (más de dos tercios del sub-tópico) seguramente pesó el protagonismo de la entonces ministra española de Medio Ambiente, Cristina Narbona, incluida por la revista Time del 24 de septiembre de 2008 entre "los 35 líderes del medio ambiente que están cambiando el mundo".

El tercer sub-tópico, "Otras medidas ecosaludables" (18\% de las noticias) engloba un popurrí de iniciativas de protección ambiental concreta (consejos para ahorrar combustible, ganadería ecológica) impulsadas por la sociedad civil y las empresas, vale decir, que no fueron promovidas por los poderes públicos.

El cuarto ítem, "Productos verdes" (4,9\% del total), se limita a coches híbridos y eléctricos. Su distante último puesto puede deberse a la reticencia de las cadenas a hacer "publicidad" gratis a artículos comerciales; o a la debilidad de la economía verde local.

\subsubsection{Protestas por motivos ambientales}

Las protestas impulsadas por ONGs o plataformas ciudadanas por causas ambientales han sido agrupadas en sub-tópicos de acuerdo a los motivos que las generaron.

Que "Vertidos y otras contaminaciones" ( $24,3 \%$ de las noticias) sea el más numeroso reafirma lo dicho acerca del legado mediático de la catástrofe del Prestige. Casi todas las piezas remitían al mismo hecho: el bloqueo de un buque gasífero en la ría de Ferrol por los mariscadores gallegos; un evento que reunía bellos paisajes, violencia y represión policial en la misma región afectada por la marea negra del citado petrolero. 
Que "Cambio climático" (17,6\%) le siga en importancia puede adjudicarse a la espectacularidad de las demostraciones y detenciones registradas durante la reunión del G-8 (once de las trece noticias de este apartado giraban en torno a esos hechos).

En el tercer lugar de "Maltrato animal" (18,9\%) influyó a ciencia cierta la ruidosa campaña por la abolición de las corridas de toros, una polémica de gran calado mediático en la medida en que afecta a un símbolo de la identidad nacional.

Le sigue "Riesgo de Irradiación" (8,1\%), referido al rechazo social a las antenas de telefonía móvil y a los tendidos de alta tensión. Los datos ilustran el desplazamiento de la aprensión a la energía nuclear hacia las fuentes de radiaciones no ionizantes.

"Normativa Ambiental" (6,7\%) recoge las manifestaciones de cazadores y agricultores, colectivos contrarios a las nuevas medidas de protección ambiental que restringen sus actividades. Igual porcentaje tuvieron las protestas contra las "Alteraciones de hábitos y hábitats", motivadas por la proliferación de topillos.

La pobre cobertura del rechazo al impacto ambiental del urbanismo $(5,4 \%)$ y a la desforestación $(4,0 \%)$ es congruente con las rezagada posiciones de ambos asuntos observadas en el tópico "Deterioro del ecosistema", y subraya su poca relevancia periodística (si la tala de árboles mereció algo de espacio fue porque una celebrity, la baronesa Tita Cervera, se opuso al derribo del arbolado del Paseo del Prado de Madrid).

Fuera de estos apartados quedaron piezas motivadas por quejas puntuales: el trazado de trenes de alta velocidad, el tráfico automotor o la suciedad de los mares.

\subsubsection{Energías renovables}

A estas informaciones las hemos clasificado aparte de "Prácticas Ecosaludables" con la finalidad de cuantificar la atención prestada a recursos considerados decisivos de cara a la reducción de las emisiones contaminantes y a la sostenibilidad, en especial en España, en donde generaron en 2008 el 29\% de la electricidad producida en el país ${ }^{9}$.

El bajo número de noticias agrupadas en este tópico ejemplifica la autonomía de los criterios periodísticos en comunicación ambiental: un recurso estratégico de la política ambiental puede no ser valorado de igual modo por las cadenas.

En este reducido espacio dominaron las referencias a los biocombustibles $(40 \%$ de las informaciones), impulsadas por la polémica acerca de su impacto en el precio de los alimentos. La controversia, sumada al interés suscitado por el primer vuelo comercial con biocombustibles, hizo que este rubro -en el que España no sobresale- gozara de mayor cobertura que la energía eólica (tres noticias), pese a que en 2008 el país se convirtió en el tercero del mundo en potencia instalada ${ }^{10}$. Ese año, asimismo, España se tornó el tercer productor fotovoltaico del planeta ${ }^{11}$; sin embargo, la energía solar apenas tuvo 7 noticias; y habrían sido menos de no mediar las llamativas vistas de coches y catamaranes propulsados por rayos solares.

La biomasa apenas mereció dos noticias, y el hidrógeno, una; el resto tuvo por objeto a las energías renovables en general y otras fuentes (maremotriz, por ejemplo).

\footnotetext{
Ver http://www.idae.es/index.php/id.70/mod.noticias/mem.detalle

10 Ver http://www.idae.es/index.php/id.70/mod.noticias/mem.detalle

11 Ver http://www.idae.es/index.php/id.70/mod.noticias/mem.detalle
} 


\subsection{La agenda ambiental}

Abordemos ahora a la cuestión final: ¿cuál fue la agenda de las cadenas españolas con estos contenidos informativos? Para responderla manejaremos distintos niveles de noticiabilidad. Ya disponíamos de un primer indicador basado en el ranking de tópicos en números absolutos de noticias (Tabla 2), ordenado de mayor a menor de la siguiente manera: "Deterioro del ecosistema"; "Biodiversidad"; "Cambio Climático"; "Prácticas ecosaludables", "Protestas por motivos ambientales" y "Energías Renovables".

El segundo indicador nos lo da el ranking de tópicos en los sumarios (Tabla 3):

Tabla 3: Porcentaje de tópicos ambientales en sumarios

\begin{tabular}{|c|c|}
\hline \multicolumn{1}{|c|}{ Tópico } & Porcentaje \\
\hline & \\
\hline Deterioro del ecosistema & $49,5 \%$ \\
\hline Biodiversidad & $22,0 \%$ \\
\hline Cambio Climático & $12,9 \%$ \\
\hline Protestas por motivos ambientales & $8,6 \%$ \\
\hline Prácticas ecosaludables & $6,2 \%$ \\
\hline Energias renovables & $0,8 \%$ \\
\hline Total & $\mathbf{1 0 0 , 0} \%$ \\
\hline
\end{tabular}

Se repite aquí la jerarquía de la tabla 2, con tres matices: el liderazgo de "Deterioro del ecosistema" se expresa con mayor contundencia (prácticamente una de cada dos noticias ambientales en los sumarios pertenecían a ese tópico); "Protestas Ambientales" desbanda de su sitio a "Prácticas ecosaludables"; y "Energías Renovables" queda reducida a la mínima expresión, un signo de su condición de material de relleno.

Un tercer indicador lo brinda el ranking de noticiabilidad de los sub-tópicos, tanto por volumen de noticias (tabla 4) como por menciones en los sumarios (tabla 4)

Tabla 4: Principales sub-tópicos por frecuencia

\begin{tabular}{|c|c|c|c|}
\hline $\begin{array}{l}\text { Número } \\
\text { de orden }\end{array}$ & Sub-tópico & $\mathbf{N}^{0}$ noticias & $\begin{array}{c}\text { Porcentaje (sobre } \\
\text { el total de noticias } \\
\text { ambientales) }\end{array}$ \\
\hline 1 & Incendios forestales & 198 & $17,6 \%$ \\
\hline 2 & Vertidos maritimos & 121 & $10,8 \%$ \\
\hline 3 & Alteración de hábitos y hábitats & 113 & $10,1 \%$ \\
\hline 4 & Cría de animales en cautividad & 63 & $5,6 \%$ \\
\hline 5 & Sequia & 58 & $5,2 \%$ \\
\hline 6 & Medidas oficiales contra el cambio climático & 53 & $4,7 \%$ \\
\hline 7 & Acciones de concienciación ambiental & 48 & $4,3 \%$ \\
\hline 8 & Especies en peligro & 46 & $4,1 \%$ \\
\hline 9 & Medidas gubernamentales de protección ambiental & 46 & $4,1 \%$ \\
\hline 10 & Nuevos datos cientificos sobre el cambio climático & 43 & $3,8 \%$ \\
\hline
\end{tabular}


Lideran esta tabla los incendios forestales, seguidos de vertidos marítimos, la alteración de hábitos y hábitats, cría de animales en cautividad, sequía y medidas oficiales contra el cambio climático (los tres primeros sub-tópicos suman la mitad de las noticias).

Pasemos a los sub-tópicos más recurrentes en los sumarios. Por la importancia estratégica que tienen los titulares de primera plana, esta clasificación revela, quizás mejor que ninguna otra, los criterios valorativos de los responsables de los informativos.

Tabla 5: Presencia de sub-tópicos en sumarios

\begin{tabular}{|c|c|c|}
\hline $\begin{array}{l}\text { Número } \\
\text { de orden }\end{array}$ & Sub-tópico & $\begin{array}{l}\text { Porcentaje de noticias } \\
\text { de cada subtópico } \\
\text { mencionadas en } \\
\text { sumarios }\end{array}$ \\
\hline 1 & Incendios forestales & $54,3 \%$ \\
\hline 2 & Acciones de concienciación ambiental & $47,8 \%$ \\
\hline 3 & Alteración de hábitos y hábitats & $43,9 \%$ \\
\hline 4 & Medidas oficiales contra el cambio climático & $28,3 \%$ \\
\hline 5 & Vertidos maritimos & $25,5 \%$ \\
\hline 6 & Cria de animales en cautividad & $23,2 \%$ \\
\hline 7 & Protestas contra vertidos & $21,9 \%$ \\
\hline 8 & Medidas gubernamentales de protección ambiental & $19,6 \%$ \\
\hline 9 & Maltrato a animales & $17,1 \%$ \\
\hline 10 & Protestas contra el cambio climático & $15,6 \%$ \\
\hline
\end{tabular}

Aquí los incendios forestales mantienen su primacía, seguidos de las acciones de concienciación (atribuible al impacto causado por la concesión del premio Príncipe de Asturias a Al Gore y del Nobel de la Paz al Intergovernmental Panel on Climate Change -IPCC-y a Gore). La alteración de hábitats y hábitos conserva su tercer puesto, y hacen lo propio las medidas gubernamentales de protección ambiental. Al cuarto lugar acceden las medidas oficiales contra el cambio climático (una posición que, como decíamos, se benefició de su difusión en cumbres internacionales); mientras los vertidos marítimos pasan a la quinta posición (un descenso indicativo de que no se trataba de accidentes graves) y la cría de animales en cautividad baja a la sexta posición en un desplazamiento revelador de su escasa noticiabilidad.

Las protestas, ausentes en la tabla 4, ocupan aquí sucesivas posiciones: el séptimo lugar, gracias a la lucha de los mariscadores gallegos; el noveno lugar, por la campaña contra la tauromaquia; y el décimo lugar (manifestaciones contra el cambio climático).

Las ausencias en la tabla 5 ilustran los asuntos que, en opinión de los editores, no sirvieron de reclamo de cara a la audiencia: sequía, especies amenazadas, riesgo de irradiación, todo lo relativo a las energías renovables, deforestación y productos verdes. 
El último indicador lo aportan los mínimos comunes denominadores de la noticiabilidad ambiental. Para identificar el "núcleo duro" de la agenda común a las cadenas nos fijaremos primero en las noticias sobre un determinado hecho que emitieron el mismo día; para, a continuación, determinar cuáles de ellas fueron incluidas en los sumarios; de tal modo conoceremos las temáticas favoritas de los editores.

En total, las cuatro cadenas coincidieron en cubrir 28 acontecimientos idénticos en una misma jornada, generando 112 noticias de las cuales 64 fueron mencionadas en los sumarios. Dieron el máximo grado de noticiabilidad a los titulares de incendios forestales (24 noticias) y vertidos marítimos (20 noticias), seguidos por los nuevos datos científicos sobre el cambio climático y las medidas oficiales para atajarlo (12 informaciones entre ambos), y, por último, a dos protestas diferentes: una contra el maltrato de los animales (cuatro noticias), y la otra contra la ley conservacionista que restringe la caza deportiva (cuatro noticias). En breve: lo más noticioso fueron las piezas sobre deterioro ambiental, cambio climático y protestas por motivos ambientales.

\section{Discusión}

\subsection{Relevancia numérica}

Que la temática ambiental apenas mereciera el 3,45\% de las noticias emitidas en prime time a lo largo de doce meses por las principales cadenas españolas demuestra su escasa relevancia para los editores ${ }^{12}$. Que tan solo una de cada 29 informaciones tocase dicho contenido parece muy poco comparado con el espacio dado a los deportes o a la política naciona ${ }^{13}$. Las escasas variaciones porcentuales entre las cuatro televisiones estudiadas confirma que este desinterés es compartido, independientemente de su carácter público o privado. En el caso de TVE, cabría preguntarse si esta reducida cobertura no entraña un incumplimiento de la función de servicio público que constituye su razón de $\operatorname{ser}^{14}$.

De todos modos, valdría la pena preguntarse si realmente la audiencia demanda más información de este tipo. La Cuarta Encuesta Nacional de la Percepción Social de la Ciencia y la Tecnología realizada en España en 2008 (FECYT, 2009) puede orientarnos al respecto: sus encuestados consideraron el medio ambiente el séptimo tema informativo más interesante de una lista de 23 tópicos. El grado de interés suscitado se situó

12 El análisis de 20.000 noticias emitidas durante 2005/2006 realizado por León (2007) arroja que el 1,45\% del tiempo de los informativos se dedicó al medio ambiente. Por su parte, Mercado Sáez (2010) identificó en su muestra un 2,2\% de noticias ambientales. Los dos parámetros empleados por uno y otro autor (duración y número de noticias) coinciden en lo mismo: el escaso espacio dedicado a la temática.

13 Un estudio de la revista Consumer (2006) sobre 16.752 noticias emitidas en enero y febrero de 2006 por TVE, A3, Tele5, Cuatro y siete cadenas autonómicas, encontró que el deporte y la política española ocuparon cada uno el 20,2\% del tiempo de emisión de los informativos.

14 RTVE dispone de dos cadenas generalistas, TVE1 y TVE2, la primera dirigida al público mayoritario, y la segunda orientada a ofrecer a una audiencia minoritaria temas distintos o no tratados por TVE1. 
en 3,59 puntos en una escala de uno -nada interesado- a cinco -muy interesado-, bastante por encima de la media. Respecto de la satisfacción con la información ambiental recibida de los medios, con arreglo a una escala de uno -nada informado- a cinco puntos -muy informado-, los entrevistados se manifestaron medianamente satisfechos, otorgándole 3,09 puntos, lo que sin embargo representa medio punto por debajo de su interés declarado por el tema (ídem, p. 197). Habría entonces una demanda -no muy elevada- que los medios no satisfacen.

\subsection{Origen de las noticias}

La información versaba en su mayoría de hechos ocurridos en España, lo que patentiza la preocupación de las cadenas por su entorno próximo, así como la capacidad de los actores locales (administraciones, científicos, ecologistas) para generar noticias. No se puede pasar por alto un factor capital: la ventaja de los acontecimientos autóctonos sobre los foráneos en cuanto a suministro rápido de imágenes y declaraciones. Que dos tercios de las noticias sean de origen nacional y un tercio provenga del exterior nos advierte que las cadenas han priorizado los retos ambientales nacionales sobre los cuales es necesaria la acción de los poderes públicos y la ciudadanía, sin caer en el provincialismo que supondría ignorar lo que sucede fuera de nuestras fronteras.

\subsection{Contenidos de las noticias}

Tres grandes grupos de tópicos, "Deterioro del ecosistema", "Biodiversidad" y "Cambio Climático", acapararon casi el 80 por ciento de las noticias.

El liderazgo cuantitativo del "Deterioro del ecosistema" corrobora que aquí también 'las malas noticias' son las que más 'venden'. Pero esta afirmación debe matizarse, puesto que la razón de ser de la información ecológica ha sido y es la de alertar del daño causado al entorno. Así como una cobertura totalmente negativa incurriría en catastrofismo e ignoraría facetas cruciales como la remediación de dichos daños, una complaciente le haría un flaco favor a la causa del medio ambiente. Por otra parte, resulta fundamental reparar en el significado de las 'malas noticias' en esta área informativa. Encuadrar como 'noticia ambiental' calamidades que antes eran etiquetadas como 'sucesos', vale decir, fatalidades sin solución, entraña un cambio sustancial de framing en la medida en que el nuevo encuadre incorpora, de modo más o menos explícito, la responsabilidad política, social o corporativa del incendio o vertido de marras. Esta diferencia de enfoque y de significaciones adheridas debe ser tenida en cuenta a la hora de evaluar la predilección de las televisiones por el dramatismo. Pero no todo son 'malas noticias'; una importante fracción de la muestra presenta una tonalidad más optimista, a saber, las referidas en los tópicos "Prácticas ecosaludables" y "Energías Renovables" y en los sub-tópicos "Cría de animales en cautiverio", "Tráfico ilegal de Especies" y "Medidas Oficiales contra el Cambio Climático", en total, el $34,2 \%$ de las piezas. Se observa entonces que las informaciones con eje en las crisis se alternaron con otras de índole preventiva o didáctica.

El otro gran conjunto lo forman las noticias sobre biodiversidad, y dentro de estas, las referidas a la fauna. A la televisión le gustan los animales, en especial los mamíferos -ungidos representantes de facto de todos los habitantes de la biosfera- y sobre 
todo los encerrados en zoos ${ }^{15}$ (en parte por las razones prácticas señaladas en 3.3.2.). Resultaría difícil precisar hasta qué punto esa afición se basa en una preocupación sincera por la suerte de los seres vivientes; lo cierto es que los ecologistas han sabido explotarla con campañas centradas en especies emblemáticas (ballenas, osos pandas, delfines...) para introducir sus peticiones en la agenda periodística.

Respecto del "Cambio climático", a la luz de los datos, el mayor desafío ambiental se ha abierto paso en los contenidos televisivos, pese a la dificultad que tal proceso plantea al formato 'noticia', estructurado en torno a eventos aislados.

La escasa dimensión de las "Protestas por motivos ambientales" -aunque con notable resonancia en los sumarios- resulta llamativa cuando se recuerda que la información ambiental surgió a caballo de la denuncia ecologista. Hoy, la cobertura televisiva continúa con las denuncias a la vez que limita el protagonismo de sus agentes tradicionales, los ecologistas. Volveremos sobre este punto en las conclusiones.

A modo de resumen: los contenidos privilegiaron el daño ecológico, el debate sobre el cambio climático y las acciones preventivas y de remediación, dejando poco espacio a la ciencia ambiental (los sub-tópicos que la recogen, "Datos científicos del Cambio Climático" y "Hallazgos científicos sobre Biodiversidad", no llegan al 5\% del total). La combinación de informaciones dramáticas y constructivas se impuso claramente sobre la transmisión de conocimientos sobre la materia.

\subsection{Criterios de noticiabilidad}

Dijimos que una de cada tres de las noticias (37,3\%) fue mentada en los sumarios de los informativos. Para valorar si esto es mucho o poco se hace necesario comparar el dato con el relieve dado a otras temáticas. Para el cotejo disponemos de dos estudios basados en la misma muestra: el primero, firmado por Martínez Nicolás et. al. (2009), arroja que el 50,6\% de los sucesos fueron citados en sumarios, así como el 40,3\% de los titulares deportivos y el $38 \%$ de los políticos; y el estudio de Francescutti et al. (2012:23), según el cual el 36\% de las noticias de salud y el 18,9\% de las piezas sobre ciencia tuvieron menciones en la front page de los noticiarios. De la comparación surge que los editores concedieron al medio ambiente una importancia algo superior a la sanidad, ligeramente inferior al deporte y la política, y muy superior a la que le otorgaron a la ciencia.

El análisis ha detectado la existencia de criterios comunes de noticiabilidad, al menos en temas como el incendio forestal, los vertidos, el cambio climático y ciertas protestas. El catastrofismo, el dramatismo y el conflicto fueron los atributos de las noticias elegidas para la front page, junto con la proximidad geográfica de los hechos referidos: gran parte de los incendios y vertidos tuvieron lugar en España; y las protestas más destacadas afectaron a dos iconos nacionales como la tauromaquia y la caza.

${ }_{15}$ No es ésta una peculiaridad de la televisión española: Knut, el cachorro de oso polar recuperado en 2006 por el zoo de Berlín, se convirtió en icono mediático alemán e internacional. Fama similar obtuvo en 2010 el pulpo Paul, el predictor de los resultados de los partidos de la Copa Mundial de Fútbol 2010. 
Aunque este trabajo no se ocupó de la dimensión visual de las noticias, se da la circunstancia de que los temas más noticiosos se distinguían, en su mayoría, por su aptitud para generar imágenes vistosas. Puede afirmarse que la espectacularidad, carga impactante y trágica belleza de bosques en llamas, mareas negras y pantanos vacíos ayudaron a las noticias a ser escogidas para los sumarios; lo mismo se aplica a las protestas: si son visualmente llamativas, como la marcha de cazadores por el centro de Madrid, o las telegénicas iniciativas de Greenpeace en las cumbres del clima, captarán la atención de las cámaras. Decir que las imágenes resultan fundamentales en televisión es una obviedad, pero el sesgo que esta obviedad introduce en la noticiabilidad de la cobertura deben tenerlo en cuenta quienes busquen promover este tipo de comunicación.

\section{Conclusiones}

En el curso del año estudiado no se produjeron desastres ecológicos ni se negociaron tratados internacionales sobre la materia; fue un periodo sin hitos ambientales, por lo que el análisis presentado vale como descripción de la cobertura televisiva en condiciones normales.

La 'radiografía' obtenida demuestra que el medio ambiente recibió escasa atención en el formato analizado: en modo alguno los informativos enfatizaron la centralidad de la crisis ecológica y los retos que conlleva (y en casos como el impacto ambiental del urbanismo, observaron un notable silencio). No obstante ello, que el volumen de la cobertura se mantuviera constante a lo largo del año -con un pico estival impulsado por los incendios forestales- evidencia que la temática ha salido de su gueto en los documentales de naturaleza, conquistando un nicho permanente en el espacio prime time, el más cotizado de la programación.

La información estudiada comparte con las demás noticias televisivas los rasgos de dramatismo, conflictividad, rareza, proximidad, culto a las celebrities (que aquí favoreció la repercusión de la prédica de Al Gore) y espectacularidad (responsable de la sobre-representación de los incendios y otros siniestros, de los animales y de las protestas); y se diferencia de aquellas por su costado educativo y preventivo, así como por el peso que tienen como protagonistas las organizaciones de la sociedad civil.

Uno de los planteamientos de la "modernización ecológica" se ha visto confirmado: la televisión española se ha apropiado del discurso ecologista, creando un espacio para la crisis ambiental en sus informativos. El lugar minoritario que ocupan en esta cobertura las acciones de los ecologistas certifica que estos han perdido el monopolio de la denuncia; su labor vigilante la han asumido ahora los científicos, las instituciones y celebrities, y sobre todo los periodistas, que la ejercen con arreglo a sus esquemas interpretativos y al servicio de sus intereses profesionales e institucionales. Tales intereses hicieron que la cobertura no se ajustara del todo al canon de la "modernización ecológica": mientras ésta se distingue por su espíritu constructivo y su apuesta por las soluciones técnicas de la crisis ambiental en el marco de la economía de mercado (Oltra. ob. cit.), dichas soluciones (patentes en "Prácticas Ecosaludables" y "Energías Renovables") recibieron poca atención por parte de los periodistas, quienes priorizaron la denuncia del daño ecológico y de las amenazas al entorno, la con- 
troversia política, las protestas y la espectacularidad al servicio de la lucha por las audiencias.

Por su naturaleza cuantitativa este estudio nada puede afirmar sobre la calidad de las noticias o de la sub-representación de ciertas áreas, aparte de proponer hipótesis. Tampoco puede dilucidar si el mensaje audiovisual era comprensible y equilibrado, si incurría en sensacionalismo, o si los 60/70 segundos de promedio que dura cada pieza alcanzaron a dar cuenta de fenómenos tan complejos (un asunto que nos conduciría a otro debate relevante: ¿deben los noticieros cumplir esa función explicativa o bastaría con que incentivasen a su audiencia a recabar información suplementaria en otros formatos?). Son algunas de las preguntas que quedan pendientes para futuros trabajos que, en cualquier caso, disponen ahora de una base empírica en la que apoyarse.

\section{Referencias}

ABDUL-WAHAB, Sabah (2008): “A preliminary investigation into the environmental awareness of the Omani public and their willingness to protect the environment", American Journal of Environmental Sciences, vol. 4 n 1, pp. 39-49.

ALLAN, Stuart, ADAM, Barbara \& CARTER, Cynthia, eds. (2000): Environmental risks and the media. London, Routledge,

ANTILLA, Liisa (2005): "Climate of Skepticism: US newspaper coverage of the science of climate change", Global environmental Change, vol. 15, n 4, pp. 338-352.

BROTHERS, Christine et al. (1991): "The impact of television news on public environmental knowledge", Journal of environmental education, vol. 22, $\mathrm{n}^{\mathrm{o}} 4$, pp 22-29.

CARABAZA, Julieta et al. (2007): "Cobertura del medio ambiente en la televisión mexicana”, Comunicación y Sociedad n ${ }^{\circ}$ 7, pp. 45-76.

COMISION EUROPEA (2007): Eurobarometer 295. En: http://ec.europa.eu/public_opinion/archives/ebs/ebs_295_en.pdf [Consultado por última vez el día 20 de febrero de 2012]

CONSUMER (2006): “Informativos de TV”, nº 98, abril, pp. 4-9.

CURTIN Patricia \& RHODENBAUGH Erik (2001): "Bulding the news media agenda on the Environment: A comparison of Public Relations and Journalistic Sources", Public Relations Review, vol. 27, $\mathrm{n}^{\mathrm{o}}$ 2, pp. 179-195.

DÍEZ NICOLÁS, Juan (2004):El dilema de la supervivencia. Los españoles ante el medio ambiente, Madrid, Caja Madrid.

FUNDACIÓN ESPAÑOLA DE CIENCIA Y TECNOLOGÍA (2009): Cuarta Encuesta Social de Percepción Social de la Ciencia. Madrid, FECYT.

FRANCESCUTTI, Pablo; MARTÍNEZ NICOLÁS, Manuel; TUCHO, Fernando (2012): La información sanitaria en los telediarios. Madrid, Almud Ediciones.

GOOD, Jennifer (2009): "The cultivation, Mainstreaming and Cognitive Processing of Environmentalist Watching Television", Environmental Communication, Vol. 3. November, pp 279-297. 
HARON, Sharifah, PAIN, Laily \& YAHAYA, Nurizan (2005): "Towards sustainable consumption: An examination of environmental knowledge among Malaysians", International Journal of Consumer Studies, vol. 29 n 5, pp. 426-436.

KOLBE, Richard \& BURNETT, Melissa (1991): "Content-Analysis Research: An Examination of Applications with Directives for Improving Research Reliability and Objectivity". Journal of Consumer Research, n ${ }^{\circ}$ 18, pp. 243-250.

KRIPPENDORF, Klaus (1980): Content Analysis. An introduction to its Methodology. London, Sage Publications.

LEÓN, Bienvenido (2007): "El medio ambiente en las televisiones españolas", en Cultura verde: ecología, cultura y comunicación. Sevilla, Junta de Andalucía, pp. 361-373.

LEÓN, Bienvenido (2010): Informativos para la televisión del espectáculo. SevillaZamora, Comunicación Social.

LESTER, Libby \& COTTLE, Simon (2009): "Visualizing Climate Change: Television News and Ecological Citizenship". International Journal of Communication, num. 3, pp. 920-93

MARTÍN LÓPEZ, Berta (2011): "Evaluación del estado de la biodiversidad en España y su papel como suministradora de servicios". Evaluación del Ecosistema del Milenio en España. Madrid, Fundación Biodiversidad.

MARTÍNEZ NICOLÁS, Manuel et al. (2009): "La información televisiva en España. Análisis de los noticiarios de las emisoras públicas y privadas", ponencia presentada en la VII Bienal Iberoamericana de comunicación. Guadalajara (México), 2325 de septiembre.

McCOMAS, Katherine et al. (2001): "Environmental Content in Prime-Time Network TV's Non-News Entertainment and Fictional Programs". Society \& Natural Resources, vol. 14, $\mathrm{n}^{\circ}$ 6, pp 533-542.

MEISTER, Mark \& JAPP, Phyllis, eds. (2002): Enviropop: Studies in environmental rhetoric and popular culture. Westport, Greenwood.

MERCADO SÁEZ, María Teresa (2010): "La cobertura de la información ambiental en la Sexta/Noticias", en LEÓN, Bienvenido (ed.): Informativos para la televisión del espectáculo, pp. 41-47.

MIKAMI, Shunji (1995): "The media coverage and public awareness of environmental issues in Japan". International Communication Gazette, vol. 54 no. 3 pp. 209-226.

MINISTERIO DE AGRICULTURA, ALIMENTACIÓN Y MEDIO AMBIENTE (2007): Los incendios forestales en España. Año 2007, http://www.marm.es/es/biodiversidad/temas/defensa-contra-incendios-forestales/incendios_forestales_espania_2007_tcm7-19478.pdf [fecha de consulta: 20 de febrero de 2007]

MUÑOZ TORRES, Juan Ramón (2002): Por qué interesan las noticias. Barcelona, Herder. 
OBSERVATORIO DE LA SOSTENIBILIDAD EN ESPAÑA (2008): Informe de Sostenibilidad en España año 2008. Madrid, Ediciones Paraninfo

OLTRA, Christian (2005): "Modernización ecológica y sociedad del riesgo", Papers, num. 78, pp. 133-149.

OSTMAN, Ronald \& PARKER, Jill (1987): “A Public's Environmental Information Sources and Evaluations of Mass Media". Journal of Environmental Education, vol. 18, num. 1, pp. 9-17.

PETERSON, Robin (1991): "Physical environment television advertisement themes: 1979 and 1989". Journal of Business Ethics, num. 10, pp. 221-228.

PRASAD, Narada et al. (2009): "Environment News Broadcast in Malaysia: An Analysis of Prime -Time News Coverage in Local Television Channels", comunicación presentada en la conferencia Development Communication in the Era of Globalization, Chennai (India), 9-11 de julio.

ROBERTS, Marilyn \& McCOMBS Maxwell (1994): "Agenda Setting and Political Advertising: Origins of the News Agenda", Political Communication, vol. 11, num. 3, pp. 249-62.

SZERSZYNSKI, Bronislaw \& TOOGOOD, Mark (2000): "Global citizenship, the environment and the media", en ALLAN, ADAM \& CARTER (eds.): Environmental risks and the media, pp. 218-228.

SHANAHAN, James \& McCOMAS, Katherine (1997): “Television's Portrayal of the Environment:1991-1995", Journalism and Mass Communication Quarterly, vol. 174 , num. 1, pp. 147-159.

TODD, Anne Marie (2002): "Prime-Time Subversion: The environmental rethoric of the Simpsons", en MEISTER, M. \& JAPP, M. (eds.): Enviropop: Studies in environmental rethoric and popular culture, pp. 63-80.

VICENTE, Miguel (2005): La información televisiva durante la crisis del Prestige: Análisis de contenido de los noticiarios de TVE1, TVE3, Antena 3 y Telecinco. Tesis doctoral, Barcelona, Universidad Autónoma de Barcelona, en: http://ddd.uab.cat/pub/trerecpro/2007/hdl_2072_3853/Treball+de+recerca.pdf [fecha de consulta: 1 de enero de 2007]

WEINGART, Peter \& ENGELS, Anita (2000): "Risks of Communication: discourses on Climate Change in Science, Politics and the Mass Media". Public Understanding of Science, vol. 9, num. 3, pp 261-283.

WILSON, Kris (1995): "Mass media as sources of global warning knowledge". Mass Communication Review, vol. 22, num. 1-2, pp 75-89. 